\title{
Determinação de vazamentos em extintores de incêndio pelo método da variação da pressão em função do tempo: bases teóricas, proposta de arranjo experimental e primeiros resultados
}

\author{
Leak detection in fire extinguishers by the pressure variation method \\ according to time: theoretical bases, proposal of experimental arrangement \\ and first results
}

Francisco Tadeu Degasperi ${ }^{1}$, Deives Junior de Paula ${ }^{1,2, *}$, Luiz Fernando Batista da Silva ${ }^{2}$, Mauricio Mattos ${ }^{1}$, Guilherme Getsch

\section{RESUMO}

Os Incêndios constituem um dos eventos mais danosos à vida e à natureza, podendo provocar tanto a perda de vidas humanas e a destruição do patrimônio, assim como a destruição de sítios ambientais. Entre os meios disponíveis para o combate ao fogo encontram-se os extintores de incêndio, criados para conter focos de proporção e intensidade pequenas de maneira rápida, imediata e segura para os usuários. Apesar de sua capacidade de combate estar limitada ao princípio de incêndio, o extintor pode ser bastante eficaz, graças à sua prontidão, combinada com a rapidez na sua utilização. Para que os extintores sejam eficazes e eficientes contra um princípio de incêndio, considerando que seu manuseio pelo usuário devidamente treinado será correto, suas características técnicas devem garantir sua confiabilidade. Um dos aspectos que frequentemente comprometem o bom desempenho do extintor de incêndio e afetam a confiabilidade e a validade desse equipamento é o vazamento de seu gás propelente. Tal vazamento, consequentemente, traduz-se na perda da pressão interna desse gás antes do término da garantia do equipamento, o que compromete seu funcionamento em caso de necessidade. Este artigo discute o vazamento de gás propelente ao longo do tempo e sua quantificação. O método usado para detectar a existência de vazamento no extintor de incêndio é o aumento da pressão em função do tempo em uma câmara de vácuo, com emprego da tecnologia de vácuo, considerando o extintor de incêndio no interior dessa câmara. O método em questão necessita de um arranjo experimental que avalie apenas um extintor de incêndio por vez. Em geral, as medições durante o experimento são realizadas no período de um a três dias, de modo que as medições obtidas sejam confiáveis. Sob o ponto de vista da aplicação em uma linha de produção de extintores de incêndio, o método aqui empregado não seria o mais apropriado para a avaliação de vazamentos. Entretanto, este artigo se justifica pelo fato de tal método verificar a ocorrência de vazamento ao longo do tempo, podendo ser utilizado como alternativa em laboratório de terceira parte (laboratórios independentes do fabricante), para uma avaliação amostral da linha de produção. Um dos objetivos principais deste texto é mostrar que o comportamento físico do vazamento do gás é bem diferente do comportamento físico de um líquido que vaza de um recipiente. Em geral, o vazamento depende da pressão e da temperatura nas quais o gás se encontra. Corroborando este objetivo, esta publicação pretende ainda apresentar uma abordagem didática sobre a modelagem matemática do vazamento de gases. Este artigo considera tanto o desenvolvimento teórico para determinar a existência e a quantificação do vazamento como a proposta de arranjos experimentais para corroborar a teoria desenvolvida.

Palavras-chave: Extintores de incêndio; Vazamento; Sistema de vácuo; Modelagem.

\section{ABSTRACT}

A fire is one of the most damaging events to life and nature, which can lead to loss of lives and the destruction of property as well as environmental sites. Fire extinguishers are among the means available to fight low-proportion and intensity fires in a fast, immediate and safe way for the users. Although its firefighting capability is restricted to the outbreak, a fire extinguisher can be very effective, due to its immediacy and readiness. In order to be effective and efficient against fire outbreaks, considering a correct handling by a properly trained user, fire extinguishers must contain aspects that address its reliability. One of the aspects that often compromise the proper performance of a fire extinguisher and affect its reliability and warranty is the leakage rate of propellant gas. This leakage rate, consequently, accounts for a loss of internal pressure before the end of the warranty, and could jeopardize its operation when needed. This paper discusses the leakage rate of propellant gas over time and its measuring. The leak detection method used in this research was the increasing of pressure according to time inside a vacuum chamber, by applying vacuum technology, considering the fire extinguisher inside the chamber. This method requires an experimental arrangement that evaluates only one fire extinguisher at a time. To take reliable measurements during the experiment, the chamber and all its instrumentation are monitored during three days. Concerning its application in a fire extinguisher production line, the employed method does not appear as the most proper way to evaluate leakage. However, this paper is justified by the fact that said method can verify the occurrence of leakage during a period of time, and can be used as an alternative in a third party laboratory for sample evaluating the production line. One of the goals of this research is demonstrate the physical difference between gas and liquid, when leaking from a pressurized container. In general, gas leakage rates depend on the pressure and temperature of the gas. Endorsing this goal, this paper intends also to present a simple approach on the mathematical modeling of gas leakage rate, and includes a proposal of experimental setup to evaluate this theoretical approach.

Keywords: Fire extinguisher; Leakage; Vacuum system; Modeling.

1.Faculdade de Tecnologia de São Paulo - São Paulo (SP) - Brasil.

2.Instituto de Pesquisas Tecnológicas do Estado de São Paulo - São Paulo (SP) - Brasil.

Autor correspondente: dpaula@ipt.br

Recebido: 01 Jun. 2019 Aprovado: 05 Ago. 2019 


\section{INTRODUÇÃO}

Incêndios estão presentes em nosso cotidiano. Independentemente de suas proporções, eles podem causar danos à vida e à natureza, além de sempre estarem associados a perdas materiais, as quais podem ser de grande monta, trazendo prejuízos em diversas esferas da sociedade ${ }^{1}$.

Recentemente, incêndios destruíram patrimônios culturais expressivos, como o Museu Nacional, localizado na cidade do Rio de Janeiro, e a Catedral de Notre Dame, em Paris, na França, a qual sofreu um incêndio parcial, mas de grandes proporções. Também podemos citar, no Brasil, incêndio recente em planta de refino de petróleo, além dos incêndios de enormes proporções na Califórnia, Estados Unidos, com danos tanto aos sítios ambientais quanto a edificações.

Indiferentemente de suas proporções, incêndios também acometem edificações residenciais unifamiliares (casas) e multifamiliares (edifícios residenciais), bem como edifícios comerciais. São noticiados incêndios nesses tipos de ocupação quase diariamente, os quais ocasionam perda material e, por vezes, de vidas humanas, trazendo prejuízos de ordem social.

A sociedade moderna dispõe de vários recursos, bem como de conhecimento incorporado às diversas normas e regulamentações vigentes, para evitar e combater incêndios de maneira eficiente e eficaz.

As disposições de segurança contra incêndio presentes nas edificações são denominadas medidas de prevenção e proteção contra incêndio. As medidas de prevenção estão associadas ao controle do risco de princípio de incêndio. Já as de proteção destinam-se a preservar vidas humanas e bens materiais contra os efeitos nocivos de um incêndio em desenvolvimento na edificação. Essas últimas medidas dividem-se em duas categorias: medidas passivas e medidas ativas ${ }^{1}$.

A proteção passiva visa manter a integridade da estrutura pelo máximo de tempo possível, evitando seu colapso até que os ocupantes possam ser retirados da edificação com segurança ${ }^{1}$.

Já a proteção ativa pode ser entendida como aquela em que, diante da ocorrência de incêndio, o sistema instalado na edificação responde aos estímulos provocados pelo fogo de maneira manual ou automática. Como exemplo, temos os sistemas de detecção e alarme de incêndio; de proteção por extintores; por hidrantes e mangotinhos; ou por chuveiros automáticos (sprinklers) ${ }^{1}$.

Dentro das medidas de proteção ativa, o extintor de incêndio é um equipamento de fácil manuseio e utilização. Se bem empregado no princípio de incêndio, é um eficiente meio de combate ao fogo.

$\mathrm{O}$ extintor de incêndio tem vantagem e importância caso a sua localização esteja devidamente compatibilizada com os riscos do ambiente. A principal vantagem dessa ferramenta é sua prontidão para uso por parte do operador - o qual terá que, por meio da identificação da ocorrência do incêndio e da natureza do material em combustão, selecionar adequadamente o tipo de extintor quanto à classe de fogo em curso para iniciar o combate. Os operadores, portanto, devem ser treinados para tal seleção e respectivo uso $^{2,3}$.
Admitindo-se que as condições de localização e de operação citadas sejam cumpridas, a confiabilidade dos extintores de incêndio é um aspecto essencial e intrínseco de cada equipamento. Em outras palavras, quando necessário o uso de um extintor dentro de seu período de garantia (ou validade), confiamos que funcionarão adequadamente.

Os extintores de incêndio - tanto os novos (dentro do período de garantia estabelecido pelo fabricante) quanto os posteriormente submetidos às ações de manutenção (realizadas após o término de tal garantia, momento em que a garantia passa a dever ser atestada pela empresa que realiza a manutenção do equipamento) - devem conter os requisitos de desempenho relativos à sua capacidade de extinguir o princípio de incêndio. Um dos problemas mais frequentes desse equipamento é a ocorrência de vazamentos fora dos limites admissíveis, fazendo com que o gás propelente armazenado no extintor seja perdido, o que prejudica a pressurização e afeta o desempenho ${ }^{3}$.

A NBR 15808:2013 (Extintores de incêndio portáteis), da Associação Brasileira de Normas técnicas (ABNT), define que os extintores de incêndio com pressurização direta não podem apresentar vazamento que ocasione pressão menor que 95\% da pressão normal de carregamento, no período de 2 anos $^{4}$.

Os possíveis pontos de vazamento podem ser: a válvula, tanto na rosca como no corpo (nas soldas do recipiente); o mecanismo de abertura; e o manômetro e sua rosca. Em geral, vazamentos afetam o desempenho do extintor de incêndio.

Esta pesquisa se propõe a desenvolver a teoria relativa ao vazamento de gases de um recipiente. São utilizadas as grandezas termodinâmicas presentes no gás propelente do interior do extintor de incêndio (temperatura, pressão e volume), bem como a quantidade total de massa ou número de moles do gás. Veremos que o vazamento de gases é mais difícil de ser estudado quanto à sua caracterização termodinâmica do que o de líquidos, dado que líquidos têm densidades constantes, diferentemente dos gases.

Neste artigo, em consequência da teoria desenvolvida para quantificar as taxas de vazamento, foi elaborada uma proposta de arranjo experimental que corrobore tanto a teoria desenvolvida quanto a realização de experiências de determinação e quantificação de vazamentos em extintores de incêndio. Serão apresentadas as grandezas termodinâmicas medidas no arranjo experimental, bem como seu modo de utilização para determinação das taxas de vazamento. Foram realizadas verificações e determinações do grau de confiança nos resultados obtidos experimentalmente.

Serão apresentados também os resultados obtidos nos ensaios com o arranjo experimental, realizados no Laboratório de Segurança ao Fogo e a Explosões (LSFEx), do Instituto de Pesquisas Tecnológicas do Estado de São Paulo (IPT), e no Laboratório de Tecnologia do Vácuo (LTV), da Faculdade de Tecnologia de São Paulo (FATEC-SP), pertencente ao Centro Estadual de Educação Tecnológica Paula Souza (CEETEPS). 
Como conclusão deste artigo, serão discutidos os resultados obtidos, além de serem oferecidas propostas de melhorias para trabalhos futuros.

\section{FUNDAMENTOS E DESENVOLVIMENTO TEÓRICO}

O extintor de incêndio é um equipamento composto, essencialmente, pelas seguintes partes: recipiente, válvula de descarga, indicador de pressão, tubo sifão e mangueira de descarga. Neste artigo, estamos utilizando como referência os extintores de pressurização direta, abastecidos com pó químico $\mathrm{ABC}$ (agente extintor) e nitrogênio (gás propelente). $\mathrm{O}$ recipiente de extintores com essa configuração possui volume específico, com capacidade para armazenar tanto o gás propelente a uma determinada pressão normal de carregamento (PNC) quanto o agente extintor (pó químico $\mathrm{ABC}$ ), correspondente à carga nominal do equipamento. Acionando-se a válvula de descarga do extintor de incêndio, o gás propelente e o agente extintor são expelidos de dentro para fora, graças à diferença entre a pressão no interior do recipiente e a pressão atmosférica do ambiente. Nesse processo, o agente extintor e o gás propelente passam pelo interior do tubo sifão, pela válvula e pela mangueira de descarga a uma vazão constante (efeito de escoamento blocado) por um determinado tempo de descarga, sendo aspergidos sobre o foco de incêndio.

O método de identificação do vazamento, também chamado de método de variação (aumento) da pressão em função do tempo, consiste em uma câmara de vácuo com medidor de pressão do tipo manômetro de membrana capacitiva, além de uma bomba de vácuo mecânica de palhetas de duplo estágio e outros componentes auxiliares, conforme mostrado esquematicamente na Fig. 1.

A temperatura foi mantida constante durante a determinação experimental do vazamento do extintor de incêndio em ambiente controlado.

O princípio físico básico do processo de determinação do vazamento consiste em acondicionar o extintor de incêndio dentro da câmara de vácuo; realizar limpeza com álcool isopropílico tanto na superfície externa do extintor de incêndio quanto na superfície interna da câmara de vácuo, prática empregada na tecnologia de vácuo; e determinar o volume externo do extintor de incêndio, ou seja, o volume correspondente a seu recipiente, sua válvula de descarga e seu indicador de pressão, que será o volume efetivamente ocupado pelo extintor no interior da câmara de vácuo.

Uma maneira segura para a determinação do volume do extintor de incêndio é o método de Arquimedes. Devemos estourar todas as bolhas de ar que surgirem na superfície externa do extintor de incêndio, bem como as que estiverem na superfície interna do recipiente graduado, durante a determinação de seu volume. O volume da câmara de vácuo também inclui o volume do interior do sensor de pressão (manômetro de membrana capacitiva).
De posse dos valores dos volumes obtidos, considerando as respectivas incertezas das medições, teremos o valor do volume disponível para o gás na montagem apresentada na Fig. 1.

Podemos representar o volume disponível para o gás como na Eq. 1.

$$
V_{D}=V_{C V}-V_{E I}
$$

Nessa equação, é o volume disponível para o gás, o volume interno da câmara de vácuo (com todos os seus volumes internos disponíveis, p. ex., o volume interno do medidor de pressão) e o volume externo do extintor de incêndio com seus componentes.

Como estamos desenvolvendo a teoria para a determinação do vazamento no extintor de incêndio, ainda não apresentaremos as incertezas das grandezas desenvolvidas. Elas serão analisadas na apresentação e na discussão do arranjo experimental, considerando o tratamento dos dados experimentais obtidos e das fontes de incertezas observadas.

Consideremos que tenha sido realizado um teste de vazamento na câmara de vácuo - com detector de vazamentos baseado em espectrometria de massa - e não tenha sido encontrado vazamento de ordem maior que $10^{-9} \mathrm{mbar} \times 1 \times \mathrm{s}^{-1}$. Quanto a isso, cabe uma observação, em geral esquecida, mas de grande importância, sobre vazamentos: mesmo com os modernos detectores baseados

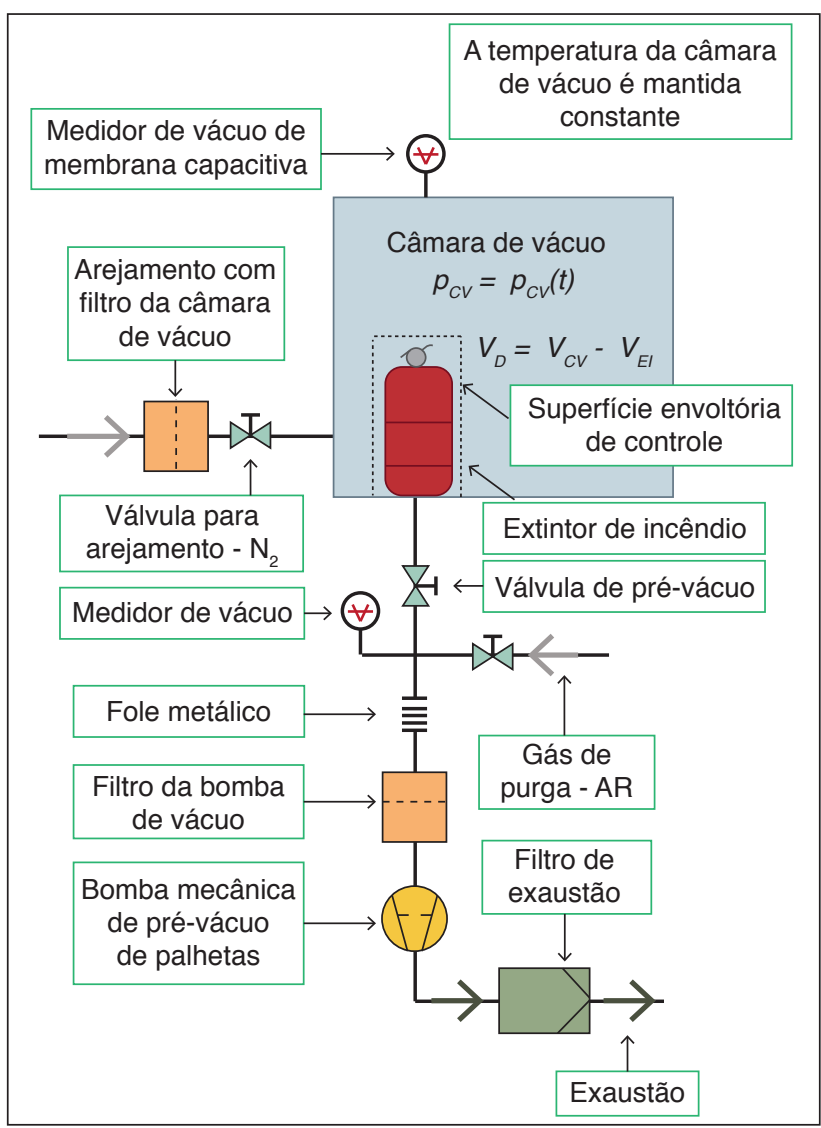

Figura 1: Desenho esquemático do sistema de vácuo usado no arranjo experimental para a determinação do vazamento pelo método de aumento de pressão em função do tempo. 
em espectrômetro de massa, com sensibilidade para aferir vazamentos da ordem de $10^{-12} \mathrm{mbar} \times 1 \times \mathrm{s}^{-1}$, quando realizamos um teste durante o qual o detector de vazamentos não tenha sido sensibilizado, não podemos afirmar que "não há vazamentos"; o máximo que podemos dizer é que "não há vazamentos maiores que $10^{-12} \mathrm{mbar} \times 1 \times \mathrm{s}^{-1}$ ". Ou seja, um extintor de incêndio pode apresentar taxa de vazamento inferior a $5 \%$ de sua pressão normal de carregamento em dois anos, conforme requisito da NBR 15808:2013

Outro aspecto importante é que, durante esse tipo de teste, podemos detectar vazamentos pequenos, que não atrapalham seu bom funcionamento, tampouco interferem em sua aplicação. Contudo, devemos ter sempre em mente que vários pequenos vazamentos concomitantes podem se traduzir em um vazamento representativamente grande para determinada aplicação. Portanto, todos os pequenos vazamentos devem ser somados a fim de compor o vazamento total na aplicação pretendida.

Diante dessas observações, pertinentes à presente pesquisa, vamos considerar que haja um vazamento proveniente do extintor de incêndio. Dessa maneira, poderemos admitir que haja taxa de transferência do gás (em inglês, throughput) com origem no extintor de incêndio. Consideraremos uma superfície envoltória (superfície de controle) ao extintor de incêndio, conforme mostrado na Fig. 1.

A taxa de transferência do gás $\left(Q_{V E I}\right)$, que tem origem no extintor de incêndio, é a taxa de transferência total desse extintor, a qual pode decorrer de diversos vazamentos (p. ex., da válvula, do indicador de pressão, das soldas etc.). A taxa de transferência do gás é definida de acordo com a Eq. $2^{5,6}$ :

$$
Q(t)=\frac{d(p \times V)}{d t}=p(t) \times \frac{d V(t)}{d t}+V(t) \times \frac{d p(t)}{d t}
$$

Considerando o modelo do gás ideal, como mostrado na Eq. $3^{7,8}$, temos que:

$$
p V=n R T
$$

Nessa equação, $p$ representa a pressão, $V$ o volume, $n$ o número de moles, $R$ a constante universal dos gases e $T$ a temperatura. Desse modo, considerando o gás propelente (nitrogênio molecular $\left[\mathrm{N}_{2}\right]$ ), admitimos que o gás no interior do extintor de incêndio obedece ao modelo do gás ideal. A aproximação é razoável, uma vez que a pressão no interior do recipiente do extintor se encontra a cerca de 10 atm $(1 \mathrm{MPa})$. Utilizaremos a modelagem matemática para o gás ideal (gás de ClapeyronMendeleev), entendendo que a equação de van der Waals poderia ser aplicada, mas o modelo matemático de ClapeyronMendeleev é apropriado à presente aplicação.

Assim, derivando em relação ao tempo os termos da equação do gás ideal, temos a Eq. 4:

$$
\begin{aligned}
& \frac{d}{d t}(p \times V)=\frac{d}{d t}(n R T) \Rightarrow p(t) \times \frac{d V(t)}{d t}+ \\
& +V(t) \times \frac{\bar{d} p(t)}{d t}=R T(t) \times \frac{d n(t)}{d t}+R \times \bar{n}(t) \times \\
& \times \frac{d T(t)}{d t}
\end{aligned}
$$

Dessa maneira, a taxa de transferência de gás pode ser escrita como:

$$
\begin{aligned}
Q(t) & =p(t) \times \frac{d V(t)}{d t}+V(t) \times \frac{d p(t)}{d t}= \\
& =R T(t) \times \frac{d n(t)}{d t}+R \times n(t) \times \frac{d T(t)}{d t}
\end{aligned}
$$

Considerando que essa equação se aplica ao recipiente do extintor de incêndio, podendo ser simplificada, admitimos que o volume de seu recipiente seja constante. Admitimos também que a temperatura tenha se mantido constante durante a experiência. Isso é possível mantendo o ambiente em condições controladas, com o uso de ar-condicionado. Nesse caso, a temperatura foi mantida a $20^{\circ} \mathrm{C}$, com variação em torno de $1^{\circ} \mathrm{C}$. Dessa maneira, a equação toma a forma da Eq. 5 :

$$
Q(t)=V \times \frac{d p(t)}{d t}=R T \times \frac{d n(t)}{d t}
$$

Tal equação, considerando o recipiente do extintor de incêndio, resulta na Eq. 6.

$$
Q_{V E I}(t)=V_{E I} \times \frac{d p_{E I}(t)}{d t}=R T_{E I} \times \frac{d n_{E I}(t)}{d t}
$$

$\mathrm{Na}$ equação apresentada, consiste na taxa de transferência do gás que tem origem no extintor de incêndio, em seu volume interno (ocupado pelo gás propelente), na pressão em que se encontra o extintor de incêndio (pressão interna), em sua temperatura e no número de moles que tem seu gás propelente.

Determinada quantidade de gás (em termos de taxa de transferência de gás; ou seja, $Q_{V E I}$ ) vazará para a câmara de vácuo. Mantendo a válvula da linha de bombeamento fechada, a pressão na câmara de vácuo aumentará. Passaremos agora ao procedimento de determinação da quantidade de vazamento do extintor de incêndio.

Caso um manômetro com suficiente número de algarismos significativos estivesse conectado a esse extintor, a determinação da quantidade de vazamento poderia ser obtida por meio da Eq. 6:

$$
Q_{V E I}(t)=V_{E I} \times \frac{d p_{E I}(t)}{d t}
$$


Ocorre que a medição direta do vazamento no extintor de incêndio teria de ser um valor de variação de pressão muito pequeno (dentro do valor da pressão de carregamento do equipamento), da ordem de $10 \mathrm{~atm}$, ou $1 \mathrm{MPa}$, o que é difícil de ser realizado para vazamentos da ordem de $10^{-2} \mathrm{mbar} \times 1 \times \mathrm{s}^{-1}$. No caso de um vazamento expressivo (para um extintor de incêndio, por exemplo, $100 \mathrm{mbar} \times 1 \times \mathrm{s}^{-1}$ ), essa medição poderia ser realizada com um manômetro instalado diretamente no extintor. Sendo assim, o que pode ser feito para determinar indiretamente a quantidade de vazamento? A ideia é bastante simples.

Inicia-se o experimento fazendo vácuo no interior da câmara até que seja atingida a pressão de $2 \times 10^{-1} \mathrm{mbar}$, após o que é fechada a válvula da linha de bombeamento. A partir daí, a expressão que rege o aumento da pressão na câmara de vácuo é dada pela Eq. 7:

$$
Q_{V E I}(t)+Q_{V C V}(t)=V_{D} \times \frac{d p_{C V}(t)}{d t}
$$

Nessa equação, representa a quantidade de vazamento na câmara de vácuo, a qual deve ser bem menor que a taxa de vazamento no extintor de incêndio. Nesse caso, é esperado que seja cerca de duas ordens de grandeza menor.

Dessa maneira, a taxa de vazamento do extintor de incêndio é dada pela Eq. 8:

$$
Q_{V E I}(t)=V_{D} \times \frac{d p_{C V}(t)}{d t}-Q_{V C V}(t)
$$

Como já vimos, $V_{D}=V_{c v}-V_{E I}$.

O valor da quantidade de vazamento $\left(Q_{v c v}\right)$ pode ser determinado também pelo aumento da pressão na câmara de vácuo vazia, expressão dada pela Eq. 9:

$$
Q_{V C V}(t)=V_{C V} \times \frac{d p_{C V V}(t)}{d t}
$$

Nesse caso, indica a pressão na câmara de vácuo vazia. No tópico seguinte, serão discutidos alguns aspectos importantes sobre a determinação do vazamento do ponto de vista experimental.

Em resumo, determinar a quantidade de vazamento a partir das grandezas associadas ao extintor de incêndio, de modo direto, é praticamente impossível. Entretanto, utilizando o gás propelente que vaza do extintor para o interior da câmara de vácuo, tornase possível quantificar o vazamento em um determinado período de tempo, uma vez que o medidor de pressão instalado na câmara de vácuo é suficientemente sensível para medir o aumento de pressão.

\section{ARRANJO EXPERIMENTAL - COMENTÁRIOS E CONSIDERAÇÕES}

Alguns aspectos do arranjo experimental são importantes para uma determinação confiável e segura do vazamento total no extintor de incêndio, ou seja, para mensurar a contribuição de todos os possíveis vazamentos provenientes do extintor. A câmara de vácuo, o sensor de pressão e a válvula da linha de bombeamento devem ser fabricados atendendo a padrões de qualidade metrológica e aplicação no intervalo de pressão de vácuo de interesse.

No tocante à câmara de vácuo, deve ser preferencialmente construída em aço inoxidável, podendo ser da linha 304 L. A solda tem de ser do tipo TIG (gás inerte de tungstênio; do inglês, tungsten inert gas), de preferência com os cordões de solda feitos no lado interno da câmara de vácuo. As vedações foram confeccionadas em elastano (Viton ${ }^{\mathrm{TM}}$ ). A Fig. 2 mostra o desenho de conjunto da câmara de vácuo montada. Foram construídas duas câmaras de vácuo iguais entre si. Observam-se, no desenho do conjunto, dois flanges do tipo KF-10; neles serão instalados o sensor de pressão e a conexão para realizar o bombeamento de gás (linha de bombeamento).

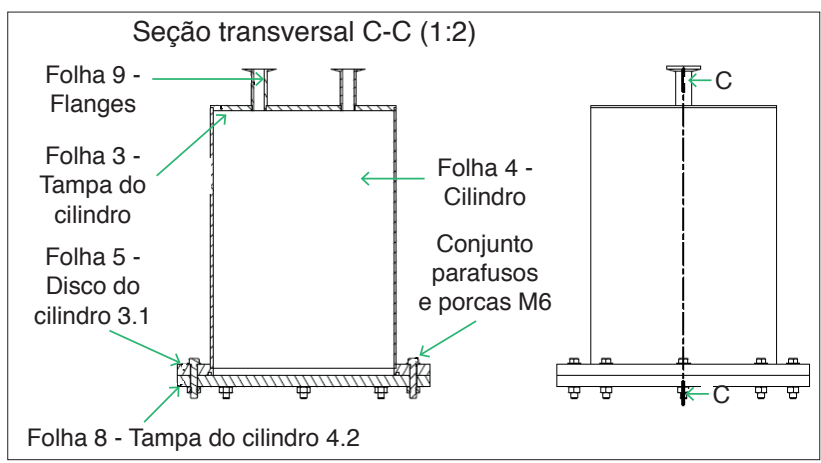

Figura 2: Desenho da câmara de vácuo individual.

Um dos objetivos para que câmaras de vácuo sejam projetadas dessa maneira é a possibilidade de ampliação do volume interno por meio do acoplamento das duas câmaras individuais. A Fig. 3 mostra as duas câmaras de vácuo montadas de modo a produzir uma única câmara, com o dobro do volume. Com isso, pretendese avaliar extintores de incêndio de dimensões maiores.

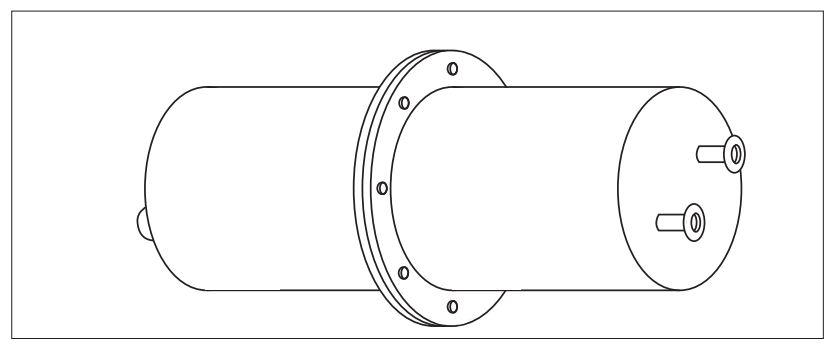

Figura 3: Desenho das câmaras de vácuo individuais montadas em conjunto.

Para bons resultados no que se refere à determinação de vazamentos, a superfície metálica da câmara de vácuo (incluindo suas tampas) precisa ser polida mecanicamente por lixamento ou mesmo - sendo a condição ideal - tratada superficialmente por eletropolimento. O objetivo dessa prática é facilitar as ações de 
limpeza, reduzindo assim as taxas de desgaseificação no interior da câmara de vácuo.

A limpeza das câmaras e suas tampas deve ser realizada com detergente e esponja macia. Após enxágue com bastante água, deve-se utilizar álcool isopropílico. Nos sistemas de vácuo, é sempre uma boa prática limpar também o exterior das câmaras de vácuo. Para acelerar o processo de secagem, as câmaras podem ser colocadas em uma estufa ventilada à temperatura de aproximadamente $70{ }^{\circ} \mathrm{C}$. O operador deve realizar todos os processos de limpeza de luvas e óculos de proteção.

Deve-se evitar o contato das mãos com as paredes do sistema de vácuo e seus anéis de vedação, pois a gordura superficial das mãos tem pressão de vapor bastante elevada, podendo assim interferir na pressão de vácuo do sistema. A Fig. 4 apresenta a foto das duas câmaras de vácuo recém-construídas, antes de receberem o polimento por lixamento mecânico.

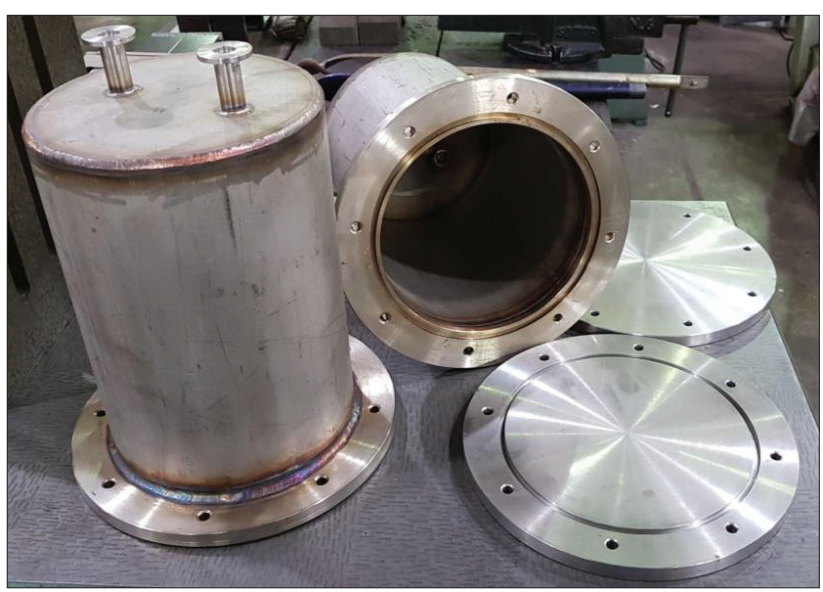

Figura 4: Foto das câmaras de vácuo sem o acabamento superficial final por lixamento mecânico.

Após receber devido tratamento superficial, bem como limpeza e secagem, deve-se realizar o vácuo em ambas as câmaras, por meio de bomba de vácuo mecânica com palhetas de duplo estágio. Espera-se, com isso, atingir pressão final de $10^{-2}$ mbar. Ver Fig. 5.

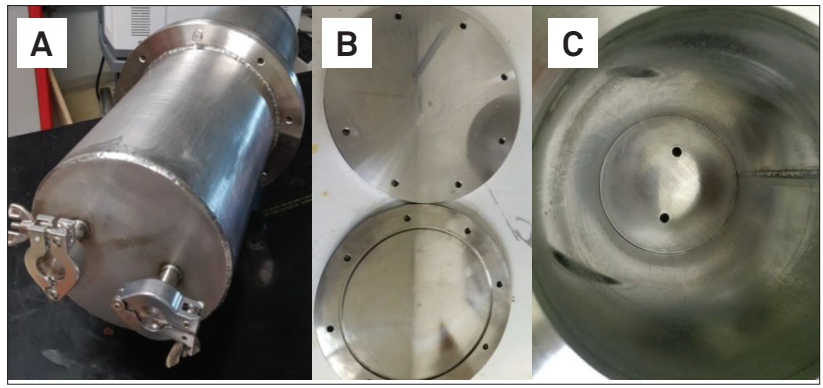

Figura 5: Foto das câmaras de vácuo. (A) Câmaras com acabamento superficial final por lixamento mecânico e limpeza com detergente e água. (B) Tampas das câmaras após limpeza. (C) Câmara após secagem em estufa.

Deve-se tomar bastante cuidado no manuseio das câmaras de vácuo, principalmente com as superfícies que serão usadas para vedação. Cuidado equivalente deve ser também tomado com as tampas das câmaras de vácuo. Caso não estejam em uso, é uma boa prática manter as câmaras com nitrogênio molecular. $\mathrm{O}$ mesmo deve ser feito quando "quebramos" o vácuo nas câmaras durante a troca dos extintores de incêndio a serem avaliados. Deve-se evitar usar ar atmosférico, pois contém poeira e vapor de água.

\section{DETERMINAÇÃO DA TAXA DE VAZAMENTO - TRATAMENTO DE DADOS EXPERIMENTAIS E ESTUDO DAS FONTES DE INCERTEZAS}

Foram apresentadas as Eqs. 8 e 9 como representadas a seguir:

$$
\begin{aligned}
Q_{V E I}(t) & =V_{D} \times \frac{d p_{C V}(t)}{d t}-Q_{V C V}(t) \\
Q_{V C V}(t) & =V_{C V} \times \frac{d p_{C V V}(t)}{d t} \\
& \text { sendo } V_{D}=V_{C V}-V_{E I} .
\end{aligned}
$$

Assim, com a determinação do vazamento na câmara de vácuo vazia $\left(Q_{V C V}\right.$, pode-se obter o vazamento no extintor de incêndio. Dessa maneira, devem-se conduzir as operações a seguir para que os dados experimentais sejam obtidos, a fim de que as taxas de vazamento $Q_{V E I(t)}$ e $Q_{V C V(t)}$ sejam determinadas.

Primeiramente, com a câmara de vácuo vazia e devidamente limpa, conforme as recomendações já apresentadas, é feito o vácuo até que se atinja pressão da ordem de $10^{-2}$ mbar no interior da câmara. Quando esse valor é atingido, fecha-se a válvula da linha de bombeamento.

A partir daí, inicia-se monitoramento do aumento da pressão em função do tempo, grandeza fundamental para a avaliação da taxa de vazamento.

É pertinente questionar por que realizar teste de vazamento com o método do aumento de pressão se o teste de vazamento foi realizado utilizando detector do tipo espectrômetro de massa na câmara de vácuo. Essa questão fica ainda mais pertinente e cabível considerando que o teste de vazamento com espectrômetro de massa fornece resultados de ordem de grandeza mais sensível do que o teste de vazamento baseado no método do aumento de pressão.

Ocorre que a câmara de vácuo será aberta e fechada várias vezes pela própria natureza do método, o que pode acarretar vazamento nas vedações com anéis de elastano (como um pequeno fio de cabelo ou acúmulo de sujidades na vedação). Portanto, é preciso certificar-se novamente quanto à presença de vazamento e sua grandeza.

Dessa maneira, os testes de vazamento com detector do tipo espectrômetro de massa foram realizados nas câmaras de vácuo empregadas nesta pesquisa, mostrando estarem em condições de uso para a detecção de vazamento dos extintores de incêndio. 
Cabe mencionar que, durante os testes de vazamento nas câmaras utilizadas no arranjo experimental, tanto empregadas individual quanto conjuntamente, observaram-se taxas de vazamento na ordem de $10^{-10} \mathrm{mbar} \times 1 \times \mathrm{s}^{-1}$. Comprova-se, portanto, que a construção da câmara com os cordões de solda apresentou taxas de vazamento que não influenciarão nas medições das taxas dos extintores de incêndio.

Por fim, de posse da medição da pressão em função do tempo na câmara de vácuo vazia, pode-se construir o gráfico pressão $\times$ tempo. Foi verificado que, em geral, a relação $p_{c v v(t)} \times$ $t$ é linear, uma vez que o fluxo de gás decorrente do vazamento na câmara de vácuo ocorre conforme fenômeno chamado fluxo (ou escoamento) blocado (em inglês, shocked flow). Esse efeito, presente na teoria aplicada a vazamentos e associado ao funcionamento dos extintores de incêndio, é interessante e importante, mas não será analisado neste artigo. Para maiores detalhes, o leitor deve consultar as referências recomendadas.

Por meio do gráfico da relação $p_{c v v(t)} \times t$, pode-se determinar o coeficiente angular da curva por meio da relação $d p_{c v v(t)} / d t$. Para determinar a taxa de transferência do gás, deve-se multiplicar esse coeficiente pelo volume interno da câmara de vácuo vazia, considerando-se todos os volumes internos agregados à câmara de vácuo, ou seja, os volumes de seus flanges e do sensor de pressão.

Para determinar a taxa de transferência do gás proveniente do extintor de incêndio para a câmara de vácuo, realiza-se o seguinte procedimento: após desfazer o vácuo com a aplicação de gás nitrogênio molecular, realiza-se a abertura da câmara de vácuo e introduz-se o extintor de incêndio, devidamente limpo, conforme procedimento já explicitado; após a inserção do extintor, fecha-se a câmara de vácuo e realiza-se o vácuo até que pressão da ordem de $10^{-2}$ mbar seja atingida. Quando isso ocorre, fecha-se a válvula da linha de bombeamento para que se inicie o monitoramento do valor de pressão em função do tempo. Com os valores obtidos, constrói-se o gráfico $p_{c v(t)} \times t$ e determina-se o valor de $d p_{c v(t)} / d t$. Dessa maneira, o valor da taxa de transferência de gás do vazamento total do extintor de incêndio é obtido, utilizando-se a Eq. 8 .

O tratamento dos dados experimentais realizados com o estabelecimento das incertezas nas medições serão, principalmente, dependentes das medições da pressão no tempo. Nesse caso, o sensor de pressão é vital para o sucesso da determinação da grandeza do vazamento.

O sensor de pressão com membrana capacitiva é o mais indicado, por sua capacidade de medir de pressões da ordem de $10^{-2}$ mbar até a pressão atmosférica. Diante disso, são, de modo geral, necessários dois sensores distintos, sendo um com intervalo de medição de $10^{-1}$ a $10^{-3}$ mbar e outro da pressão atmosférica até $10^{-1}$ mbar.

Em função da natureza do método adotado, o tempo necessário para realizar a medição da pressão com quantidade suficiente de pontos experimentais para a construção de uma reta, de modo a determinar sua inclinação, será dependente da grandeza do vazamento. Assim, para um vazamento pequeno, a reta será praticamente paralela ao eixo dos tempos (sendo que o vazamento na câmara de vácuo vazia é praticamente inexistente).

Os sensores de pressão de membrana capacitiva, em suas medições, coletam medições de pressão com algarismos significativos, suficientes para a construção de uma reta muito bem-definida. A medição do tempo também pode apresentar uma incerteza bastante pequena. Dessa maneira, coletando-se os valores dos volumes com pequena incerteza, conseguem-se os valores dos vazamentos bem determinados.

Como em qualquer processo de medição, devem ser considerados os limites intrínsecos. Conforme mencionado anteriormente, o método de aumento de pressão para determinação de vazamento em tecnologia do vácuo ainda apresenta número menor de aplicações. O detector de vazamento com espectrômetro de massa, na atualidade, possui maior número de aplicações em diversos segmentos.

\section{ALCANCE E LIMITES DO MÉTODO DE DETECÇÃO DE VAZAMENTOS}

Todo processo ou método de medição, qualquer que seja a grandeza física, tem alcance (ordens de grandeza nas quais atua) e limite (valor da incerteza). Em geral, o valor da incerteza depende da medição realizada. Esses fatores são aplicáveis aos sensores de pressão e são fundamentais para a realização de uma medição segura e confiável, bem como para o estabelecimento de sua incerteza.

Neste artigo, o interesse voltou-se às medições e aos cálculos necessários para determinar o valor do vazamento pelo método do aumento de pressão em função do tempo em recipiente condicionado, sendo conhecido o valor do volume disponível para o gás.

Para um extintor cuja pressão normal de carregamento (PNC) é $10 \mathrm{~atm}$ (10.000 mbar, aproximadamente), a PNC pode chegar até 9.500 mbar (mbar) em dois anos. Ou seja, dois anos $\times 3,15 \times 10^{-7} \mathrm{~s} /$ ano $=6,31 \times 10^{-7} \mathrm{~s}$. Determina-se, portanto, a redução (perda) de pressão pela Eq. 10:

$$
\Delta P_{M}=P N C-0,95 \times P N C
$$

É importante enfatizar que o volume a ser considerado no cálculo da taxa de transferência é aquele disponível para o gás, devendo ser descontados os volumes internos que o gás não pode ocupar. No caso do extintor de incêndio, deve ser descontado o volume do agente extintor (p. ex., o volume ocupado pelo pó químico seco). Assim, a taxa de transferência de gás máxima $\left(Q_{M}\right)$ de um extintor de incêndio com volume interno de 1 litro pode ser determinada utilizando-se a modelagem matemática da Eq. 7, considerando o critério de perda de pressão expresso na Eq. 10 . 


$$
\begin{gathered}
Q_{M}=V_{E I} \times \frac{\Delta P_{M}}{\Delta t}=1 \times \frac{\left(10^{4}-9,5 \times 10^{3}\right)}{6,31 \times 10^{7}}\left[\frac{\mathrm{mbar} \times l}{\mathrm{~s}}\right] \Rightarrow \\
Q_{M}=7,9 \times 10^{-6} \frac{\mathrm{mbar} \times \mathrm{l}}{\mathrm{S}}
\end{gathered}
$$

Caso o volume do extintor fosse 2 litros, o valor máximo da taxa de transferência de gás $\left(Q_{M}^{\prime}\right)$ seria:

$$
\begin{aligned}
& Q^{\prime}{ }_{M}=V^{\prime} \times \frac{\Delta P_{M}}{\Delta t}=\frac{2 \times\left(10^{4}-9,5 \times 10^{3}\right)}{6,31 \times 10^{7}} \\
& {\left[\frac{\mathrm{mbar} \times l}{S}\right] \Rightarrow Q^{\prime}{ }_{M}=1,59 \times 10^{-5} \frac{\mathrm{mbar} \times \mathrm{l}}{\mathrm{S}}}
\end{aligned}
$$

Ou seja, como o recipiente, nesse caso, tem o dobro do volume em relação ao caso anteriormente calculado, para que a pressão se reduza a $95 \%$ do valor inicial com o mesmo tempo de vazamento, a taxa deve ser o dobro daquela presente no recipiente com volume de 1 litro. Vale ressaltar que a temperatura foi mantida constante durante os cálculos, o que merece ser discutido mais profundamente.

Caso ocorra alteração de temperatura, por meio da equação de estado dos gases ideais $(p V=n R T)$, a pressão variará linearmente com a temperatura, mantendo-se o volume e o número de moles constantes. Cabe esclarecer que, quando há aumento da temperatura do extintor de incêndio, além de ocorrer o aumento da pressão do gás propelente, ocorre também a dilatação de todo o corpo do recipiente, além de aumento do tamanho geométrico do vazamento. Com isso, a taxa de transferência de gás aumenta graças a dois fatores: o aumento da pressão do gás propelente do extintor de incêndio e o tamanho geométrico do vazamento.

Para que o método proposto no presente artigo fosse verificado, foi desenvolvido arranjo experimental que ilustrasse o assunto. A temperatura foi mantida praticamente constante durante o processo de determinação do vazamento pelo método do aumento de pressão. Foram também levadas em consideração todas as premissas e recomendações para a realização dessa determinação por meio do emprego de câmara de vácuo vazia. Ver Fig. 6 .
A Fig. 7 mostra a variação temporal da pressão e da temperatura em uma câmara de vácuo vazia durante três dias) de experimento. O volume disponível para o gás no interior da câmara de vácuo vazia foi de 71,5 \pm 0,5 litros. Com os dados experimentais mostrados na Fig. 7 e o valor do volume disponível, é possível determinar a taxa de transferência do gás para o intervalo de tempo considerado, no caso, $Q_{V A Z}$.

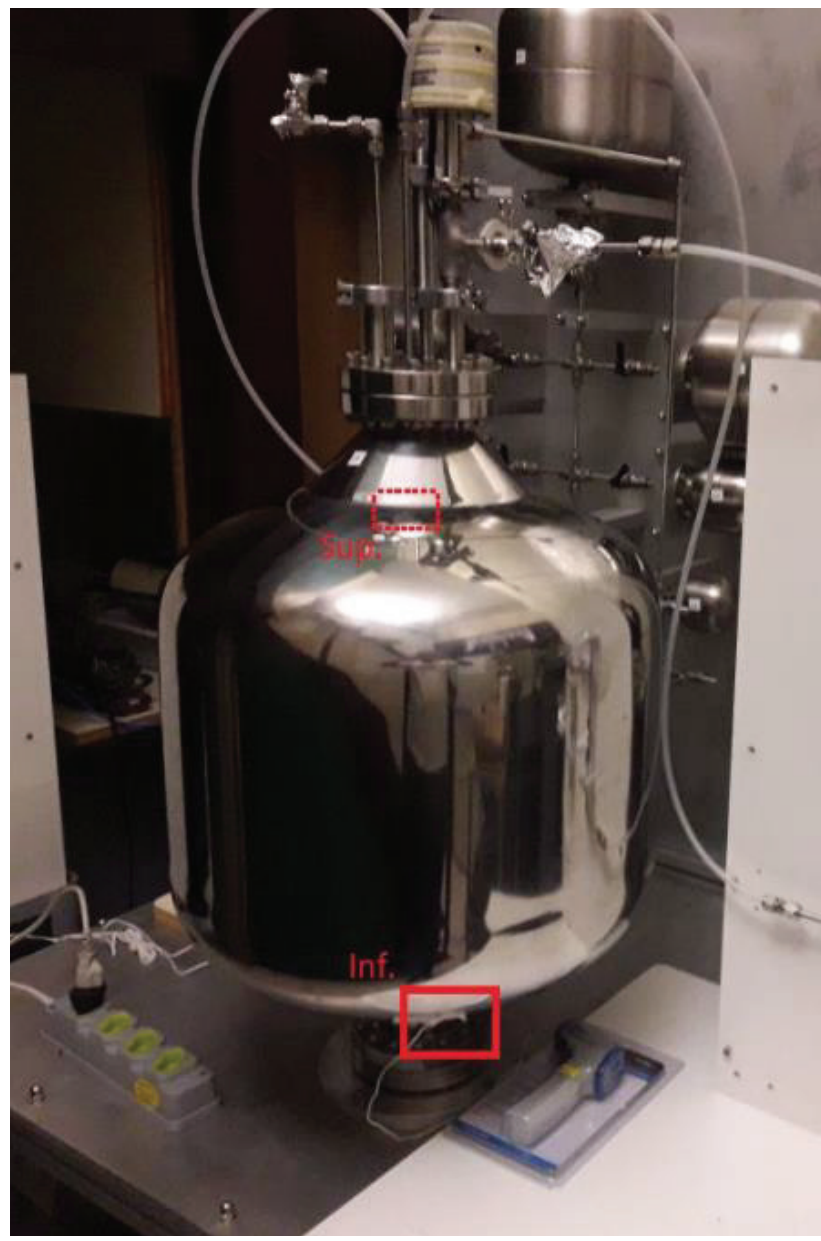

Figura 6: Foto do arranjo experimental utilizado para o desenvolvimento das bases teóricas.

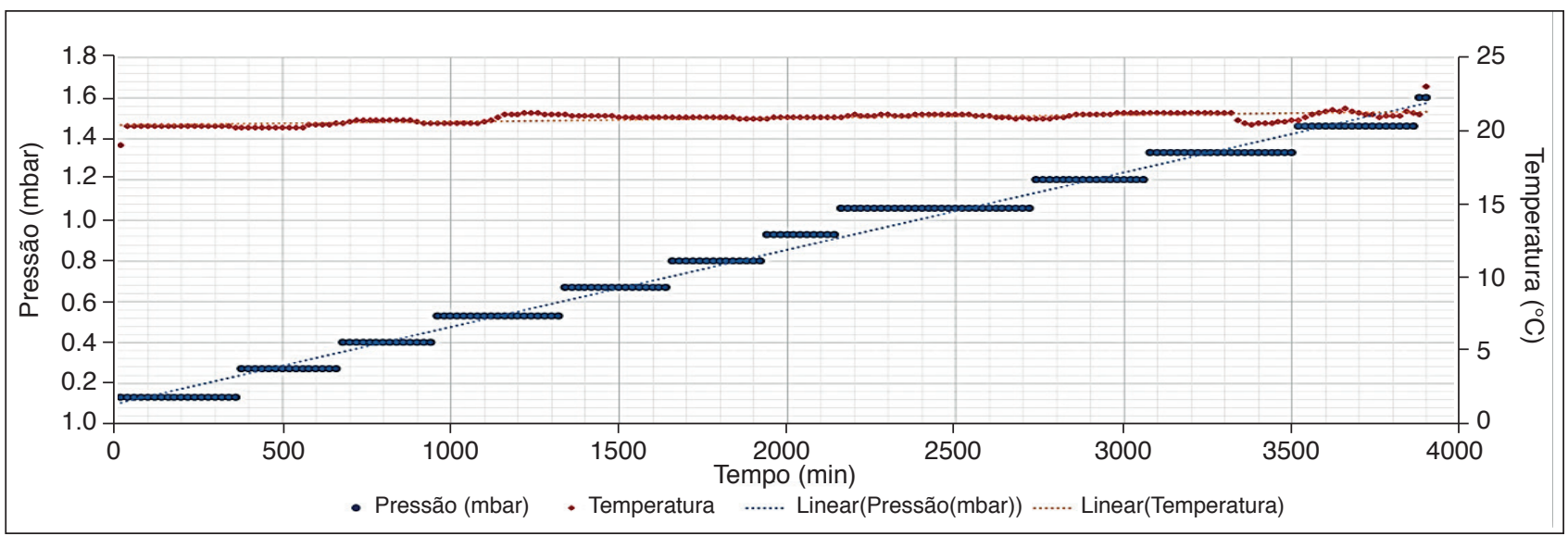

Figura 7: Variação da pressão e temperatura durante experimento com câmara de vácuo vazia. 
Assim, calculando $Q_{V A Z}$, temos,

$$
\begin{gathered}
Q_{V A Z}=V_{C V V} \times \frac{\Delta P_{C V}}{\Delta t}=71,5 \times \frac{(1,6-0,13)}{2,34 \times 10^{5}}\left[\frac{\mathrm{mbar} \times l}{s}\right] \Rightarrow \\
Q_{V A Z}=4,5 \times 10^{-4} \frac{\mathrm{mbar} \times l}{\mathrm{~s}}
\end{gathered}
$$

Como pode ser observado na Fig. 7, ocorreu aumento de 1,47 mbar $\left(6,3 \times 10^{-6} \mathrm{mbar} \times \mathrm{s}^{-1}\right)$ na pressão da câmara após 2,34 $\times 10^{5} \mathrm{~s}$ (três dias) de experimento. Apesar de o aumento ser muito baixo para cada segundo transcorrido, ele explica que os valores de pressão no gráfico $p_{C V}(t) \times t$ estejam representados em conjunto de pontos dispostos em trechos horizontais (de 0 - $400 \mathrm{~min}$ ), aumentando, posteriormente, para outro trecho horizontal (400 - $680 \mathrm{~min})$ - o que ocorre sucessivamente até o término do experimento e reproduz uma característica do sensor de pressão, o qual não é suficientemente sensível para medir e acompanhar o aumento de pressão na câmara de vácuo com taxa de $\Delta p_{C V} / \Delta t=6,3 \times 10^{-6} \mathrm{mbar} \times \mathrm{s}^{-1}$. No método aqui apresentado, há necessidade de realizar a medição de pressão continuamente, em todos os instantes do experimento. Medições de pressão realizadas apenas em instantes pré-definidos ou randomicamente resultariam em registro falho dos valores de pressão, com pontos experimentais que não capturariam o fato de o sensor de pressão não ser sensível o bastante para o valor de $\Delta p_{C V} / \Delta t$.

Os valores de temperatura obtidos durante os quase três dias de experimento foram estáveis, com variações muito pequenas, apresentando pontos experimentais bastante confiáveis.

Cabe mencionar que não foram representadas as incertezas, tanto nos dados experimentais quanto nos resultados alcançados por meio de cálculo, dado que esta pesquisa objetiva gerar dados experimentais e os respectivos modelos físico-matemáticos para o cálculo das grandezas procuradas relacionadas ao vazamento.

\section{CONCLUSÕES, COMENTÁRIOS FINAIS E PESQUISAS FUTURAS}

Neste artigo, foi apresentada uma proposta de arranjo experimental de concepção simples para determinação e quantificação de vazamentos em extintores de incêndio. A pesquisa também teve como objetivo apresentar um modo de quantificar o vazamento de gás, uma vez que, no estado gasoso, o material não tem densidade constante.

Dessa maneira, para quantificação do vazamento de um gás, é necessário levar em consideração, na grandeza, também o valor da pressão, ao contrário do que ocorre com líquidos, cuja densidade é praticamente constante. Foi possível também desenvolver a teoria necessária à quantificação de vazamentos pelo método de aumento da pressão no tempo.

Além disso, pôde-se discutir sobre o alcance e o limite do método apresentado. Observou-se que, para uma taxa de variação de pressão da ordem de $10^{-6} \mathrm{mbar} \times \mathrm{s}^{-1}$, considerando aproximadamente três dias de experimento, a taxa de transferência de gás do vazamento é da ordem de $10^{-4} \mathrm{mbar} \times 1 \times \mathrm{s}^{-1}$. Considera-se esse o limite do método aqui empregado, ou seja, o menor vazamento possível, respeitando tanto a sensibilidade dos medidores de pressão quanto o tempo de realização do experimento.

Apresentou-se um exemplo de aplicação do método de aumento de pressão e as fontes de incertezas foram analisadas, bem como as medições das grandezas necessárias (p. ex., volume, pressão e tempo).

O experimento proposto demonstra que a medição de pressão é o aspecto mais importante para a determinação confiável da taxa de vazamento e de sua incerteza (dentro dos limites apresentados e discutidos). Esse experimento mostrou, claramente, o papel da sensibilidade do sensor de pressão.

Como proposta para futuras pesquisas, considera-se a determinação da taxa de transferência de gás dos vazamentos de diferentes modelos de extintores de incêndio, variando-se sua carga nominal e, consequentemente, seu volume total. Pode-se também aprofundar o estudo sobre a influência da temperatura nos experimentos realizados, além de se explorar quais seriam os métodos de detecção de vazamentos adequados à cada atividade, tanto das empresas fabricantes de extintores de incêndio quanto daquelas que realizam suas manutenção e recarga.

Constatou-se que o método de aumento de pressão não é adequado à verificação de vazamentos em extintores de incêndio em linha de produção, uma vez que existem métodos capazes de verificar a máxima taxa de transferência de gás nesses vazamentos no tempo de até $10 \mathrm{~s}$ com a aplicação da tecnologia de vácuo e a utilização do espectrômetro de massa. $\mathrm{O}$ método aqui apresentado pode ser empregado como alternativa, considerando seus limites de aplicação, para avaliações amostrais da linha de produção.

\section{AGRADECIMENTOS}

Agradecemos ao Prof. Dr. Nilberto H. Medina e ao físico Celso Perego, ambos do Departamento de Física Nuclear do Instituto de Física da USP, pela disponibilização do espectrômetro de massa e o respectivo acompanhamento da avaliação do vazamento intrínseco às câmaras de vácuo empregadas na proposta apresentada neste projeto. Agradecemos também à Fundação de Apoio ao IPT (FIPT) pelo apoio e o patrocínio desta pesquisa de capacitação.

\section{REFERÊNCIAS}

1. Berto AF. Medidas de proteção contra incêndio: aspectos fundamentais a serem considerados no projeto arquitetônico dos edifícios. São Paulo. Dissertação [Mestrado em Arquitetura] - Faculdade de Arquitetura e Urbanismo da Universidade de São Paulo, FAU-USP; 1991. 351p.

2. Berto, AF, Paula DJ. Avaliação de extintores de incêndio. Rev. Emerg. 2017;30:34-41. 
3. Berto AF., Paula DJ., Bottger IF. Segurança contra Incêndio? Parte I. Rev. Emerg. 2018;30:p. 46-55

4. Associação Brasileira de Normas Técnicas. Extintores de incêndio portáteis: requisitos. Rio de Janeiro: ABNT; 2013. NBR 15808:2013. 73p.

5. Degasperi FT. Modelagem e análise detalhadas de sistemas de vácuo. Campinas. Dissertação [Mestrado em Engenharia Elétrica] - Faculdade de Engenharia Elétrica e de Computação da Unicamp; 2002
6. Degasperi, FT. Contribuições para análise, cálculo e modelagem de sistemas de vácuo. Campinas. Tese [Doutorado em Engenharia Elétrica] - Faculdade de Engenharia Elétrica e de Computação da Unicamp; 2006.

7. O'Hanlon JF. A user's guide to vacuum technology. 3rd ed. New York: Wiley-Interscience, 2003. https://doi. org/10.1002/0471467162

8. Lafferty JM., editor. Foundations of vacuum science and technology. New York: John Wiley and Sons Inc.: 1998. 